Pathologe 2010 · [Suppl 2] 31:324

DOI 10.1007/s00292-010-1388-9

Online publiziert: 15. September 2010

(c) Springer-Verlag 2010

\section{J. Frege \\ Berlin}

\title{
Gottfried W. Dominok
}

18.01.1932 - 25.07.2010

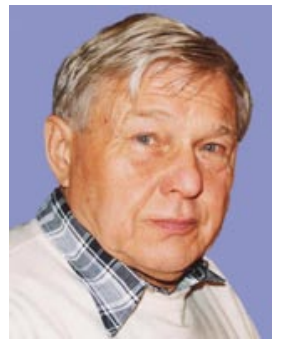

Gottfried W. Dominok

Am 25. Juli 2010 verstarb Professor Dr. Gottfried W. Dominok im Alter von 78 Jahren in Cottbus.

Gottfried Dominok wurde am 18. Januar 1932 in Königshütte/Oberschlesien geboren. Nach dem Abitur studierte er ab 1952 Medizin, zunächst in Leningrad (heute St. Petersburg), danach an der Universität Leipzig, wo ihm 1957 die ärztliche Approbation erteilt wurde und wo er unter Vorlage der Dissertation „Zur Altersund Geschlechtsbestimmung an der Morphologie der menschlichen Schädelkalotte" 1958 promovierte. Seine Weiterbildung zum Facharzt für Pathologische Anatomie absolvierte er von 1958 bis 1962 in Berlin.

Im Jahre 1962 wurde er zum Oberarzt am Institut für Pathologie der Medizinischen Akademie Dresden ernannt. Er habilitierte sich dort im Jahre 1965. Das Thema seiner Habilitationsschrift lautet „Der altersbedingte Strukturumbau menschlicher Knochen (feingewebliche Untersuchungen an über 1600 menschlichen Knochen)“. In Dresden wurde er 1966 als Dozent berufen, 1971 zum 1. Prorektor gewählt und zum 1. September 1972 als O.ö. Professor für Pathologische Anatomie berufen.

Sein besonderes wissenschaftliches Interesse galt frühzeitig der Osteopathologie. Professor Dominok übernahm
1966 in enger Kooperation mit Klinikern und Radiologen die Leitung des im gleichen Jahr gegründeten Knochentumorregisters in Dresden, wobei von Beginn an die computerunterstützte Erfassung der Knochentumoren erfolgte. Zusammen mit H.-G. Knoch veröffentlichte er die Monographie „Knochengeschwülste und geschwulstähnliche Knochenerkrankungen“" (Jena 1971), ein auf der Sammlung des Dresdener Registers basierendes Lehr- und Arbeitsbuch, von dem in den Folgejahren weitere Auflagen erschienen und das auch große internationale Anerkennung erfuhr. So erschien auch 1985 eine Ausgabe in polnischer Sprache.

1975 wurde er Direktor des Instituts für Pathologie am Bezirkskrankenhaus Cottbus (später Carl-Thiem-Klinikum) und 1976 Vorsitzender der Zentralen Fachkommission Pathologische Anatomie in der DDR. Auch das Knochenregister übersiedelte nach Cottbus. Mehr als 10.000 Fälle, darunter etwa 2500 primäre maligne Knochentumoren wurden erfasst. Aus dem Registermaterial entstanden zahlreiche Publikationen und etwa 50 Dissertationen. Gemeinsam mit Jesserer und Pape veröffentlichte er das Buch „Nomina Osteoarthrologica“ (Leipzig 1980).

Professor Dominok widmete sich in Cottbus auch der Umweltpathologie und den Einflüssen einer industriell bedingten Fluoridemission auf das Knochengewebe. Im Jahre 1992 gründete er eine Praxis für Pathologie mit reger Konsiliartätigkeit insbesondere auch auf dem Gebiet der Knochentumoren.

Professor Dominok war 1973 Mitbegründer der Arbeitsgemeinschaft für Knochentumoren in Heidelberg. Er war Grün- dungsmitglied und Vorsitzender der Gesellschaft für Osteologie der DDR sowie Generalsekretär der Europäischen Gesellschaft für Osteo-Arthrologie (EGOA). Von 1984 bis 1988 war er Vorsitzender der Gesellschaft für Pathologie der DDR und seit 1990 Mitglied der Deutschen Gesellschaft für Pathologie. Im Jahre 1972 wurde ihm der Rudolf-Virchow-Preis verliehen.

In der Pathologischen Anatomie setzte Professor Dominok neue Maßstäbe, insbesondere in der Osteopathologie, der Umweltpathologie und der kooperativen Tätigkeit mit Klinikern und Radiologen, stets mit dem Ziel, weitere Forschungsergebnisse in der Epidemiologie, Diagnostik und Therapie der Knochentumoren zu gewinnen und die Prognose maligner Knochentumoren zu verbessern.

Wir ehemaligen Mitarbeiter, deren berufliche Entwicklung Professor Dominok prägte und ganz wesentlich förderte, werden ihm stets ein ehrendes Andenken bewahren.

\section{Jörg Frege, Berlin}

\section{Korrespondenzadresse \\ Dr. J. Frege}

Zietenstr. 19, 12249 Berlin

jfrege@web.de

Interessenkonflikt. Der korrespondierende Autor gibt an, dass kein Interessenkonflikt besteht. 